\title{
Evaluation of a Diagnostic Decision Support System for the Triage of Patients in a Hospital Emergency Department
}

\author{
JC Nazario Arancibia1*, FJ Martín Sanchez², AL Del rey Mejías, J Gonzalez del Castillo², J Chafer Vila- \\ plana $^{1}$, MA García Briñon², MM Suárez-Cadenas ${ }^{1}$, J Mayol Martínez¹, G Seara Aguilar ${ }^{1}$ \\ ${ }^{1}$ Innovation Unit, Hospital Clínico San Carlos, IdISSC, Madrid (Spain) \\ ${ }^{2}$ Emergency Department, Hospital Clínico San Carlos, IdISSC, Madrid (Spain) \\ Received 13 December 2017 | Accepted 27 March 2018 | Published 20 April 2018

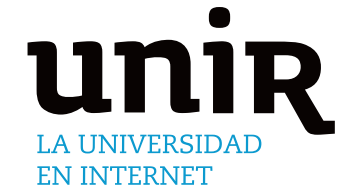

ABSTRACT

KEYWORDS

One of the biggest challenges for the management of the emergency department (ED) is to expedite the management of patients since their arrival for those with low priority pathologies selected by the classification systems, generating unnecessary saturation of the ED. Diagnostic decision support systems (DDSS) can be a powerful tool to guide diagnosis, facilitate correct classification and improve patient safety. Patients who attended the ED of a tertiary hospital with the preconditions of Manchester Triage system level of low priority (levels 3, 4 and 5), and with one of the five most frequent causes for consultation: dyspnea, chest pain, gastrointestinal bleeding, general discomfort and abdominal pain, were interviewed by an independent researcher with a DDSS, the Mediktor system. After the interview, we compare the Manchester triage and the final diagnoses made by the ED with the triage and diagnostic possibilities ordered by probability obtained by the Mediktor system, respectively. In a final sample of 214 patients, the urgency assignment made by both systems does not match exactly, which could indicate a different classification model, but there were no statistically significant differences between the assigned levels $(\mathrm{S}=0.059, \mathrm{p}=0.442)$. The diagnostic accuracy between the final diagnosis and any of the first 10 Mediktor diagnoses was of $76.5 \%$, for the first five diagnoses was $65.4 \%$, for the first three diagnoses was $58 \%$, and the exact match with the first diagnosis was 37.9\%. The classification of Mediktor in this segment of patients shows that a higher level of severity corresponds to a greater number of hospital admissions, hospital readmissions and emergency screenings at 30 days, although without statistical significance. It is expected that this type of applications may be useful as a complement to the triage, to accelerate the diagnostic approach, to improve the request for appropriate complementary tests in a protocolized action model and to reduce waiting times in the ED.

Computer Aided

Diagnostic Decision

Support System,

Emergency Triage,

Emergency Service.

\section{INTRODUCTION}

$\mathrm{T}$ RIAGE is the first evaluation and classification process used to prioritize the serious patients that arrive at the Hospital Emergency Departments (HED), its usefulness is accentuated by the considerable demand for care, with frequent congestions of services, in a context of limited resources.

In Spain, with data referring to all public and private hospitals, visits to the HED grew from 17.9 million in 1997 (449.5 visits per 1,000 inhabitants/year) to 24.4 million in 2005 (553, 1 visits per 1,000 inhabitants/year), with an average annual increase of $2.6 \%$ during that period [1]. Most of this increase is attributed to a disproportionate increase in patients who use Emergency Department (ED) inappropriately. This often results in saturation of HED [2]. According to the most recent data published by the Ministry of Health, Social Services and Equality, the number of emergencies attended in 2016 in the hospitals of the National Health System was 21.5 million, of which $11.3 \%$ required hospital admission [3]. These voluminous

* Corresponding author.

E-mail address: jcnazario@shealth.eu figures justify the development of different triage scales to offer safer, easier and more organized assistance.

Currently, there are several classification models adapted to the emergency area and validated for adults, such as: the Australian classification scale "Australasian Triage Scale (ATS)", the Canadian classification and severity scale of the emergency department (CTA), the system triage of Manchester "Manchester Triage System (MTS)", the Emergency Severity Index (ESI) and the Andorra Triage Model (MAT). The latter was adopted as a standard reference for the Spanish Triage Model [4].

It is required that classification systems have the ability to define the most appropriate initial location and reasonable attention times, but they are also expected to help predict the clinical evolution and the patient's resource needs, so that they can contribute to a more efficient management of the emergency service [5].

Some studies have documented a good correlation between the level of classification and the hospital admission index, the duration of the stay in emergencies, the requirements in the consumption of diagnostic resources and even with the survival at 6 months [6-9].

Regarding hospital admissions, research has focused mainly on the development of scales with high negative predictive value at nonurgent levels, compromising the positive predictive value for more 
severe cases and resulting in hospital admission rates that vary widely, with percentages as different as $15 \%-90 \%$ in the urgent levels of the scale. Therefore, the correct classification of high complexity cases continues to be a challenge [5]. But so is the case of less complex cases, responsible for the frequent saturation of emergency services.

Most authors have tried to calculate, with limited results, the probability of hospital admission based on individual variables such as the subjective feeling of the doctor and/or nurse [7-9], the hemodynamic situation of the patient [10] or the levels of severity assigned by the classification systems [11]. One of these models was developed in our hospital after the retrospective analysis of 2476 visits, depending on age, sex, reason for consultation, initial location and the existence of prior treatment or the need to perform complementary tests in the emergency services [12].

On the other hand, misdiagnosis is more likely in emergency departments, and this can involve serious injury or death [14-16]. Almost half of the main diagnostic errors are the result of an incorrect evaluation by the medical staff, either due to erroneous collection of medical history $(10 \%)$, errors in the physical examination $(10 \%)$ and decision logic with the patient (30\%) [17]. More research is needed to develop tools to prevent misdiagnosis [18].

Along with this approach, there has been a proliferation of more sophisticated programs, known as symptom analysers, that attempt to provide patients with a potential diagnosis and direct them to the appropriate care setting. With the use of computerized algorithms, through a series of questions or the introduction of symptoms, these programs give the user a list of possible diagnoses ordered by probability [19].

The symptom analysers have two functions: pre-diagnosis and classification. The prediagnosis presents the patient with a range of diagnoses that can be adjusted to their symptoms. The classification function tells the patient what kind of attention should be sought and with what level of urgency [20].

Although this validation focuses on the field of external hospital emergency, symptom analysers also provide access to the medical diagnostic approach in low-resource settings, such as in rural or developing countries. Active medical cooperation with symptom analysers can help improve public health [21]. These tools can also help people who can not use telephone triage or who are too insecure to access a care center without an appointment. A study showed, as early as 1976, that people are more honest about their drinking habits compared to a computer than with a doctor, and in a 1994 trial, pregnant women shared more problems with a computer than with an obstetrician [22]. Diagnostic support tools could be useful to prevent misdiagnosis and improve patient safety. General decision support systems have been developed in a technically rigorous way in computer laboratories, but, to a large extent, they are not used because they have paid little attention to the workflow of the place where they will be used [23]. Although there are few studies on the specific success factors of diagnostic decision support systems, a recent systematic review found that the most predictive feature of their success was "the automatic provision of decision support as part of the clinical workflow". In the analysis of our use case, we have used an approach that can offer a greater chance of success in this integration in the workflow in the emergency services, collecting the data directly from the patients before their meeting with the doctor [24-25].

\section{A. Description of the Application Used}

Mediktor ${ }^{1}$ is an application designed to facilitate and speed up the medical diagnostic process. Through artificial intelligence algorithms

1 Mediktor is a registered trademark of Teckel Medical; Mediktor Corp, Barcelona, Spain. that guide the patient's interrogation in a similar way to how a doctor would do it, Mediktor obtains diagnostic forecasts, establishes a level of urgency, and suggests the medical specialty indicated for each patient. The system collects demographic data of the patient (gender, age), geolocation, season of the year, vital signs, previous illnesses and medication if applicable. Using sophisticated natural language interpretation algorithms, it recognizes the reason for consultation as expressed by the user without the need to use specialized language and initiates a series of questions about symptoms and signs, until a list of pre-diagnoses is presented and a level of priority is assigned.

Considering the results of the aforementioned study carried out in the HED of our hospital, both on prediction of hospital admission, and on detection of high risk of poor outcomes [12], we added some variables to the original Mediktor record in order to evaluate its applicability to the patient segment included in this use case. These variables include the patient's need for help in basic activities, and if these needs have increased during the acute process that leads to emergencies, their cognitive and sensory situation (memory and vision), the previous use of medication, recent hospital admissions, the reason for consultation, the location in the ED, and the need for additional tests or to establish treatment in the ED.

\section{B. Objective and Context of the Study}

The main objective of this study was to determine, in a group of urgent patients of low complexity, the level of coincidence between the pre-diagnoses generated by Mediktor and the diagnosis at discharge or admission issued by the physician in the ED. The secondary objectives were to evaluate the effect of Mediktor's diagnostic concordance on hospital admissions; to compare the allocation recommended by Mediktor and by Manchester, and to ascertain any relationship with the frequency of admissions and discharges, readmissions, postemergency visits, and mortality during the 30 days following the evaluation. In addition, to evaluate the relation of the triage with the possible predictive variables of admission and to describe the duration of the different phases of the stay in the emergency room.

The study was developed as a collaboration between the Emergency Department and the Innovation Support Unit of Hospital Clínico San Carlos (HCSC) in Madrid. Teckel Medical made available the Mediktor tool and its maintenance during the study, as well as the results data of its algorithms necessary for the analysis.

\section{Methodology}

\section{A. Study Design}

The validation was designed as a prospective observational cohort study performed in the Emergency Department of the HCSC, a reference hospital with 960 beds of high complexity. The study was approved by the HCSC Research Ethics Committee. ${ }^{2}$

In the ED, the triage of hospital emergencies is carried out by nurses following the Manchester triage method. A series of consecutive patients attending the Emergency Department between 3/15/2017 and 4/10/2017 were selected.

\section{B. Inclusion/Exclusion Criteria}

To participate in the study, the subjects had to fulfil all the following requirements: Assignment of levels 3, 4 or 5 in the triage according to the Manchester assessment scale; access to the Emergency Service without documented prior medical evaluations; Age 18 or older; ability to give informed consent and to grant it and reason for consultation reported in the triage evaluation among the 5 most frequent: dyspnoea, chest pain, gastrointestinal haemorrhage, general discomfort or abdominal pain.

2 Opinion CI 16/508-E, November 16, 2016. 
To be excluded from the study, subjects had to meet the following requirements: patients assigned to levels 1 and 2 in the triage, according to the Manchester assessment scale and participation in a pharmaceutical research study during the previous 30 days.

\section{Methods for Data Acquisition and Coding}

After the acceptance of the informed consent, the Mediktor software generated a randomized code with 6 digits, which was registered manually in a separate file, for its later relation with data of the patient's clinical history. This register was kept under custody by clerical personnel of the Emergency Department, without access for the research team.

The results of the Mediktor triage for each patient were stored in a coded electronic database, without any personal identification data except the random code. Independently, in a different physical location, and without access to Mediktor, the outcome variables of the clinical history established in the protocol were collected, and later matched to the Mediktor data, using the random code mentioned above.

In the analysis stage, subjects without an explicit record of diagnosis at discharge were excluded, as were those in whom the final diagnosis was described as a symptom or sign (Diagnostics not admitted in the ICD-10), those in which by mistake the same code was identified for two patients, and cases with diagnoses not included in the Mediktor database at the time of the study. After filtering data from the 307 patients registered in the system, a final valid sample of 214 patients was obtained (Fig. 1).

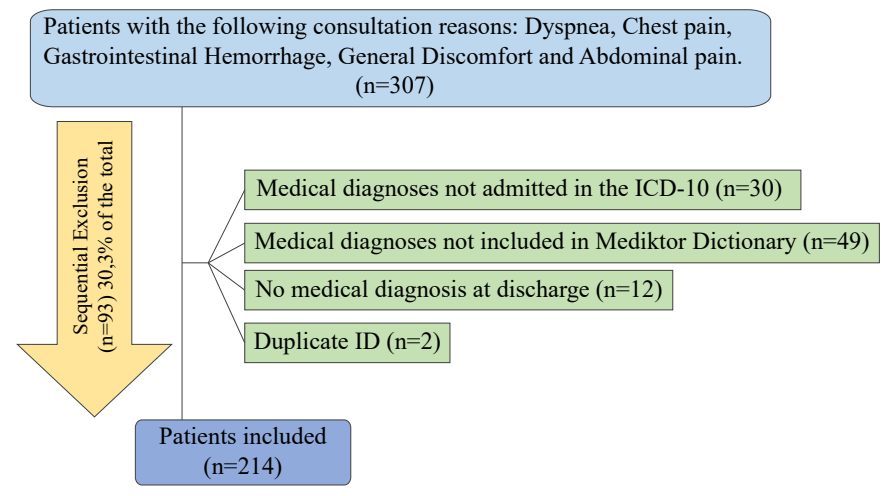

Fig. 1. Flow diagram of the methodology to identify the included patients.

Given the paucity of studies, to obtain a precision of $5.0 \%$ in the estimation of a proportion by means of a normal $95 \%$ bilateral asymptotic confidence interval, assuming a percentage of losses of $10 \%$ and with the proportion estimated in the literature of the $58 \%$ (26), a necessary sample size of 289 patients was estimated.

\section{Variable Results}

The main outcome variable was the agreement between the diagnosis established by the Mediktor software and the final diagnosis of the patient. The final diagnosis of the patient was defined as the one that would appear first in the patient's hospital discharge report, the Emergency discharge report, if this occurs, or the hospital discharge report for those patients who required hospital admission.

All patients were followed 30 days after the event to determine the secondary variables, that is, hospital readmission, emergency visit or death.

All the patients were in low complexity (First Assistance Unit, FAU) of the Emergency Department and the triage level awarded by the Manchester system was collected.

The length of stay was recorded from admission until the first medical evaluation was received, from admission to medical diagnosis until discharge.

\section{E. Methods}

The study was conducted over a period of three weeks, from March 15 to April 10, 2017, until the recruitment period was completed (n $=307$ patients). All the patients who went to the Emergency Service of the San Carlos Clinical Hospital were selected as possible study subjects, from 8 am to $10 \mathrm{pm}$, for the indicated reasons for consultation. The patients were previously triads (Manchester 3, 4 or 5 levels) and located in the UPA following the usual process. After corroborating the inclusion/exclusion criteria, a nurse from the Innovation Unit specifically assigned to the study, was presented to the patients while they waited in the waiting room to be attended, and they were accompanied to an appropriate office for the interview. He explained clearly and without technicalities the objective of the study and its observational nature, emphasizing to the patient how his participation in the study would not interfere or influence the process, the length of stay, the diagnosis, the complementary tests or the treatment. He was offered the possibility to participate in the study by asking the patient and/or guardian for his informed consent to participate and was given a copy of it.

Once included, they were interviewed by the Mediktor software, in a computer exclusively dedicated to the study. The nurse performed the suggested questions and recorded the patient's own answers, clarifying any doubts that might arise, but without interfering with their answers. The interview guided by Mediktor began with the variables and the main reason for consultation recorded in the Manchester triage, followed by the sequence of questions until generating a level of complexity of the urgency and a list of possible pre-diagnoses. At the end of the interview, the patient was thanked for his participation without showing him the possible pre-diagnoses so as not to interfere in the usual care process, and he was asked to wait again in the waiting room to receive the usual assistance. The results collected by the research nurse were not shared with any healthcare professional during the data collection phase and were only shared with the rest of the team's researchers in the analysis phase after the closing of the data collection period.

After 30 days of the interview of the last patient recruited in the study, the information system records of the Emergency Service (SISU) of the HCSC were reviewed to corroborate the diagnosis of discharge or hospitalization, the level of triage, the revisits to emergencies and the times of stay in the emergency room. The HCSC Admission database (HP HIS) was reviewed.

\section{F. Statistical Analysis}

For descriptive purposes, quantitative variables will be expressed as means and standard deviation or median and interquartile range; and the qualitative variables will be expressed as number and frequencies. To check the main hypothesis, we have evaluated by means of a binomial test that compares the agreement of the Mediktor diagnosis against the possibility of random success for the 548 diagnoses included in the Mediktor database.

For the secondary hypotheses we use the Chi-square test or the Fisher exact test (in case more than $25 \%$ of the expected frequencies were less than 5). To evaluate the relationship between ordinal quantitative variables we have used the Spearman Correlation.

In all hypothesis contrasts, the null hypothesis with an error of less than 0.05 will be rejected. The statistical analysis will be carried out with the help of the statistical package SPSS 20.0®.

\section{RESULTS}

In the descriptive analysis, we show the socio-demographic characteristics, reason for consultation, emergency room and followup of HUS patients (Table I). 
TABLE I. Description of THE SAMPle

\begin{tabular}{|c|c|c|}
\hline & & n (214 Patients) \\
\hline \multirow{2}{*}{ Sex } & Male & $88(41,1)$ \\
\hline & Female & $126(58,9)$ \\
\hline Age & & $52,13(19,41)$ \\
\hline \multirow{4}{*}{$\begin{array}{l}\text { Reason for } \\
\text { Consultation }\end{array}$} & Abdominal Pain & $94(43,9)$ \\
\hline & General Discomfort & $60(28)$, \\
\hline & Chest Pain & $34(15,9)$ \\
\hline & Dyspnea & $26(12,1)$ \\
\hline \multirow{2}{*}{ Destiny } & Hospital Discharge & $193(90,2)$ \\
\hline & Hospital Admission & $21(9,8)$ \\
\hline \multirow{5}{*}{$\begin{array}{l}\text { Length of stay } \\
\text { (minutes) }\end{array}$} & $\begin{array}{l}\text { Length of Stay until first } \\
\text { medical examination }\end{array}$ & $45,00(34,75-66,00)$ \\
\hline & $\begin{array}{r}\text { Length of the stay until the } \\
\text { medical diagnosis }\end{array}$ & $215(159-314,75)$ \\
\hline & $\begin{array}{l}\text { Length of stay at } \\
\text { emergency department }\end{array}$ & $283,50(200,75-433,25)$ \\
\hline & $\begin{array}{r}\text { - Length of stay at } \\
\text { emergency department/ } \\
\text { Hospital Admission } \\
\text { Patients }\end{array}$ & $471(351-1000,50)$ \\
\hline & $\begin{array}{r}\text { - Length of stay at } \\
\text { emergency department } \\
\text { /Hospital Discharge } \\
\text { Patients }\end{array}$ & $260(196,50-389)$ \\
\hline \multirow{3}{*}{ Follow-up } & $\begin{array}{l}\text { Re-admission/Hospital } \\
\text { Discharge up to } 30 \text { days }\end{array}$ & $6(3,1 \%)$ \\
\hline & $\begin{array}{l}\text { New visit to ED/Hospital } \\
\text { Discharge up to } 30 \text { days }\end{array}$ & $28(14,5 \%)$ \\
\hline & Mortality up to 30 days & $0(0 \%)$ \\
\hline
\end{tabular}

\section{A. Diagnostic Agreement}

The main objective of the study was to evaluate the concordance of the Mediktor diagnoses with the final diagnosis of the HUS patients, as a possible tool to support the decision. Because Mediktor offers a total of 10 pre-diagnoses classified by probability, we have divided our results into 4 different levels of agreement.

If we took any of the 10 pre-diagnoses (Top10), the level of agreement was $76.5 \%$. Considering any of the first 5 pre-diagnoses (Top5), the level of accuracy was $65.4 \%$ and for any of the first 3 prediagnoses (Top3) it was 58\%. The exact correctness in the first prediagnosis (Top1) was obtained in $37.9 \%$. All of them were statistically significant $\mathrm{p}<0.001$ (Table II).

TABLE II. Diagnostic Agreement

\begin{tabular}{|lcc|}
\hline $\begin{array}{l}\text { Position of the right diagnose at } \\
\text { Mediktor's Ranking }\end{array}$ & $\begin{array}{c}\text { Marginal \% } \\
\text { of Accuracy }\end{array}$ & $\begin{array}{c}\text { Aggregated \% } \\
\text { of Accuracy }\end{array}$ \\
\hline $\mathbf{1}^{\mathbf{0}}$ & 37,9 & $\mathbf{3 7 , 9}$ \\
\hline $\mathbf{2}^{\mathbf{o}}$ & 13,1 & 51 \\
\hline $\mathbf{3}^{\mathbf{o}}$ & 7 & $\mathbf{5 8}$ \\
\hline $\mathbf{4}^{\mathbf{0}}$ & 5,1 & 63,1 \\
\hline $\mathbf{5}^{\mathbf{0}}$ & 2,3 & $\mathbf{6 5 , 4}$ \\
\hline $\mathbf{6}^{\mathbf{0}}$ & 3,7 & 69,1 \\
\hline $\mathbf{7}^{\mathbf{0}}$ & 2,3 & 71,4 \\
\hline $\mathbf{8}^{\mathbf{0}}$ & 1,4 & 72,8 \\
\hline $\mathbf{9}^{\mathbf{0}}$ & 2,3 & 75,1 \\
\hline $\mathbf{1 0}^{\mathbf{o}}$ & 1,4 & $\mathbf{7 6 , 5}$ \\
\hline
\end{tabular}

As secondary objectives, there was no statistically significant relationship between Mediktor's diagnostic concordance and the percentage of hospital admissions [Top1-9.9\% $\left(\chi^{2}=0.001 ; \mathrm{p}=0.981\right)$; Top3- 8.9\% $\left(\chi^{2}=0.296 ; \mathrm{p}=0.587\right)$; Top5- 8.6\% $\left(\chi^{2}=0.705, \mathrm{p}=0.401\right)$ and Top10-9.1\% $\left.\left(\chi^{2}=0.353, \mathrm{p}=0.553\right)\right]$.

There were no statistically significant differences in other secondary objectives, such as the relationship between diagnostic concordance and readmissions in the emergency department [Top1- $2.5 \%\left(\chi^{2}=\right.$ $1907, \mathrm{p}=0.167)$; Top 3- 4.8\% $\left(\chi^{2}=0.055, \mathrm{p}=0.815\right)$; Top 5- 5.0\% $\left(\chi^{2}\right.$ $=0.016, \mathrm{p}=0.898)$; and Top 10-4.9\% $\left.\left(\chi^{2}=0.099, \mathrm{p}=0.753\right)\right]$.

Because we did not have any deaths in the sample, we can't determine the relationship between the number of emergency visits and mortality during the first 30 days after discharge.

\section{B. Comparison between Triage Manchester and Mediktor}

We determined the relationship between the level assigned by the Manchester triage and that of Mediktor, and there was no statistically significant relationship between them $(\mathrm{s}=0.059, \mathrm{p}=0.442)$, so it is necessary to deduce that they perform a different triage. We show the correspondence of the triages in Table III.

Table III. Classification Correspondences between Triage Manchester AND MEDIKTOR

\begin{tabular}{|c|c|c|c|c|c|c|c|}
\hline & \multicolumn{6}{|c|}{ Triage Mediktor } & \multirow[b]{2}{*}{ Total } \\
\hline & & 1 & 2 & 3 & 4 & 5 & \\
\hline \multirow{4}{*}{ 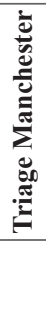 } & 3 & $\begin{array}{c}4 \\
(5,60 \%)\end{array}$ & $\begin{array}{c}11 \\
(15,50 \%)\end{array}$ & $\begin{array}{c}33 \\
(46,50 \%)\end{array}$ & $\begin{array}{c}20 \\
(28,20 \%)\end{array}$ & $\begin{array}{c}3 \\
(4,20 \%)\end{array}$ & 71 \\
\hline & 4 & $\begin{array}{c}1 \\
(0,70 \%)\end{array}$ & $\begin{array}{c}26 \\
(19,30)\end{array}$ & $\begin{array}{c}66 \\
(48,90 \%)\end{array}$ & $\begin{array}{c}31 \\
(23 \%)\end{array}$ & $\begin{array}{c}11 \\
(8,10 \%)\end{array}$ & 135 \\
\hline & 5 & $\begin{array}{c}1 \\
(12,50 \%)\end{array}$ & $\begin{array}{c}0 \\
(0 \%)\end{array}$ & $\begin{array}{c}2 \\
(25 \%)\end{array}$ & $\begin{array}{c}3 \\
(37,50 \%)\end{array}$ & $\begin{array}{c}2 \\
(25 \%)\end{array}$ & 8 \\
\hline & Total & $6(2,8 \%)$ & $\begin{array}{c}37 \\
(17,30 \%)\end{array}$ & $\begin{array}{c}101 \\
(47,20 \%)\end{array}$ & $\begin{array}{c}54 \\
(25,20 \%)\end{array}$ & $\begin{array}{c}16 \\
(7,50 \%)\end{array}$ & 214 \\
\hline
\end{tabular}

Regarding the correspondence between levels 3, 4 and 5 of the Manchester and Mediktor systems, more than half of the patients (61.1\%) classified by the Manchester system in Level 4 correspond to Level 3 of Mediktor, while $28.7 \%$ are in Level 4 . More than half of the patients classified in Level 3 by the Manchester system $(58.9 \%)$ are classified by Mediktor in Level 3,35.7\% in level 4 and $5.4 \%$ in level 5. The correspondences found (Fig. 2) do not reach statistical significance. $(\mathrm{p}=0.211)$.

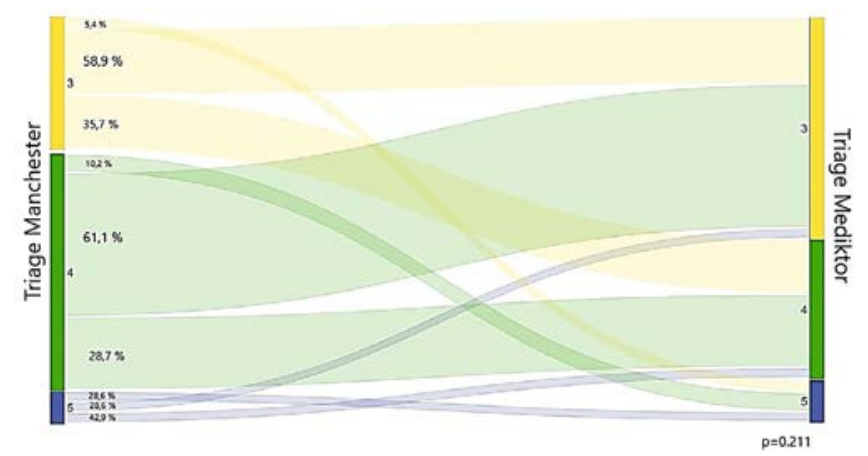

Fig. 2. Classification correspondences in levels 3, 4 and 5.

In the group of patients discharged (Fig. 3), the patients classified with the greatest severity (Level 3) by Mediktor presented a higher percentage of hospital admission (76.5\%) with respect to Levels 4 and $5(11.8 \%)$, respectively. The Manchester system presents a statistically significant higher percentage of hospital admission in Level 4 (52.4\%) than in Level 3 (42.9\%). In neither of the two cases is there a significant relationship $(\mathrm{p}=0.034)$. 


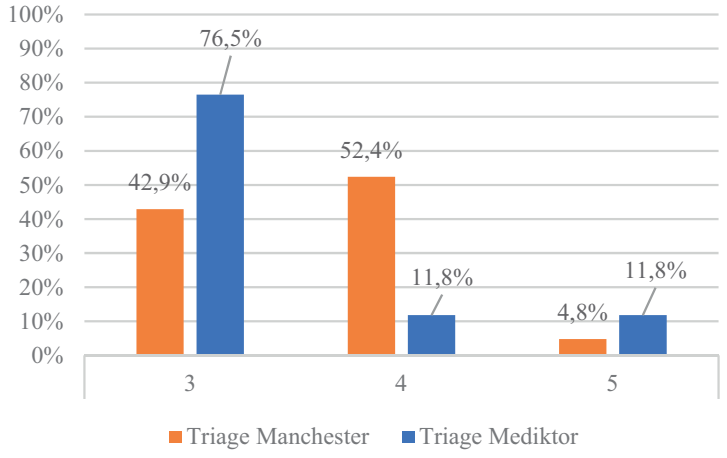

Fig. 3. Hospital Admission according to classification of triage.

The stay in the emergency room from admission until discharge or hospital admission of the patient had a median of $285.5 \mathrm{~min}$. (RIC; 200434.25). The stay in the emergency room until the first consultation by the emergency doctor registered a median of $45 \mathrm{~min}$. (RIC, 33,7566,00 ), and the stay until the diagnosis a median of $218 \mathrm{~min}$. (RIC, 159.75-324.25). The stay in emergency was greater in the patients who were admitted [476 min. (RIC, 356-1302, 75)] compared to patients discharged [median 263 min. (RIC; 199.25-389). Significant statistical difference was found between these groups. ( $\mathrm{p}<0.001)$.

\section{Possible Predictive Variables of Hospital Admission}

We determined the difference between patients who presented one or more possible predictive variables of admission in previous studies and those who did not, without finding significant differences $\left(\chi^{2}=3.91\right.$, $\mathrm{p}=0.272$ ). There was no statistically significant relationship between the possible predictive variables of admission and the patient's hospital admission:

- Take 3 or more drugs per day: $11.1 \%$ of hospital admission (IH) $\left(\chi^{2}=0.303, p=0.582\right)$.

- Need for help with basic activities: $0 \%$ of $\operatorname{IH}\left(\chi^{2}=1.032, \mathrm{p}=0.310\right)$.

- Need for more help than usual after the start of the acute process that he visits in the Emergency Room: $40 \%$ of $\mathrm{IH}\left(\chi^{2}=4.01\right.$, $\mathrm{p}=0.405)$

- Memory problems: $0 \%$ of IH $\left(\chi^{2}=0.137, \mathrm{p}=0.712\right)$.

- Good vision: $16.7 \%$ of IH $\left(\chi^{2}=0.303, p=0.582\right)$.

- Hospital admission in the last 6 months: $16 \%$ of IH $\left(\chi^{2}=0.569\right.$, $\mathrm{p}=0.451)$.

\section{Tracking}

The follow-up variables were measured in the group of discharged patients. In Fig. 4 it is shown that the Mediktor classification presents the highest number of hospital readings at 30 days in level $3(83.3 \%)$ and decreases in the following levels (Level 4: 16.70\% and in Level 5: $0 \%$ ). In contrast to the Manchester Triage system, which presents a higher level of readmission, Level 4 (66.70\%), followed by $33.30 \%$ at level 3. In any case, there were no statistically significant differences $(p=0.361)$ between the classification scales and the patient's hospital readmission.

In the 30-day urgency follow-up (Fig. 5), the Mediktor triage behaviour indicates that the greater the urgency in the classification, the higher the percentage of emergency department visits (Level 3: 50\%, Level 4: 45.8\% and Level 5: 4.2\%). Unlike the Manchester System, which presents a higher percentage of revisits to emergencies at 30 days in Level 4 (75\%), followed by $21.4 \%$ in Level 3 and finally $3.6 \%$ in Level 5 . No there were statistically significant differences ( $p$ $=0.585$ ) between the classification scales and the 30 -day patient's emergency visit.

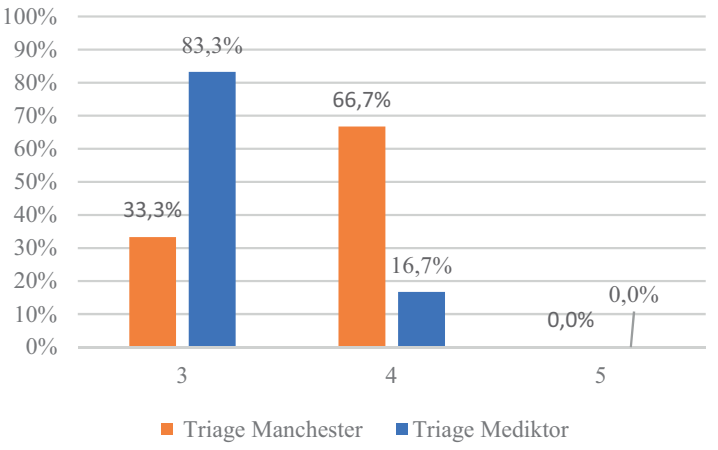

Fig. 4. Hospital readmissions at 30 days in discharged patients.

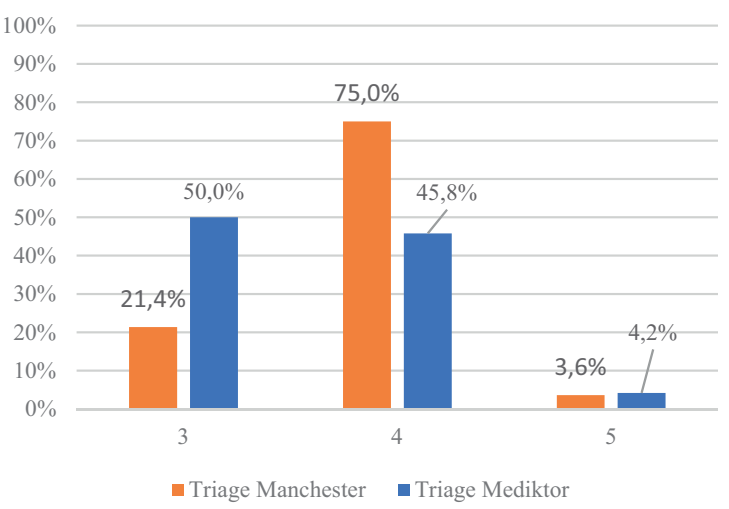

Fig. 5. New visit to ED in 30 days in patients discharged.

\section{DisCUSSION}

The present work did not include all emergency episodes, but only those initially classified in Manchester triage as low priority and treated in the First Assistance Unit, which excluded specialties such as paediatrics, traumatology, gynaecology and obstetrics, psychiatry, ophthalmology, otorhinolaryngology and all those patients who were initially located directly in the Acute Ward, corresponding to Levels I and II of triage. This means that, as indicated in the presentation of the project, the conclusions cannot be generalized to any emergency patient.

In our study, the percentage of hospital admission was $9.8 \%$, and severity levels according to the Manchester triage system were not directly proportional to the percentage of hospital admission (Yellow Level 3: 42.9\%, Green - Level 4: 52.4\% and Blue - Level 5: 4.8\%). It must be considered that triage with the Manchester System is a process and not a result and its main objective is to reduce the variability of urgent care by assigning the most appropriate level for that care, and that its validity is susceptible to changes related to the age and other circumstances [27]. The complexity of the patient does not depend exclusively on the level of urgency of the triage, but on other variables, such as age, reason for consultation, comorbidity, baseline and cognitive capacity. In addition, it uses exclusively clinical discriminators; For example, severe pain is a subjective discriminator that classifies the patient at a high level of severity, even if hospitalization is not necessary. The behaviour of Mediktor in the classification of severity levels is close to what is expected with the percentage of hospital admission (Level 3: 76.5\%, Level 4: 11.8\% and Level 5: 11.8\%). The scope of Mediktor in the collection of data is greater, so a different classification model is expected, although without statistically significant differences in this sample size based on a study that used case simulations [26] when not finding similar studies. 
In the development of this pilot, the actual validated sample corresponds to $69.7 \%$ of the sample calculated a priori, with a percentage of loss that rose to $30.3 \%$ due to different causes (Fig. 1). Future studies with a larger number of patients will be necessary, considering the percentage of losses from this study and previous studies [29].

Regarding the diagnostic agreement, previous research suggests that, at the present time, symptom analysers may be less effective than physicians in terms of diagnostic accuracy [29], to conclude that the superiority of physicians over symptom analysers could be, in fact, excessive, especially if what we are considering as "gold standard" is the emergency medical diagnosis that, according to some studies, can pick up errors in $18 \%$ of patients [30] and could be total or partially true, compared to the final diagnosis of the patient, in only $71.4 \%$ of the cases [31]. The implantation of electronic medical records could imply a significant improvement in diagnostic accuracy and safety, although their results vary depending on the scenarios in which it is applied and the profile of the professionals $[32,33]$, especially at a time when the use of new data extraction technologies for natural language processing in the health field allows us to better understand our health actions [34].

This is because the diagnostic accuracy of the symptom analysers can be improved after appropriate feedback. One reason that the diagnostic accuracy is not optimal is that there is no accurate database to continuously feedback the diseases in the database. When continuous feedback is obtained from diagnoses and symptoms validated by physicians, the symptom analysers will update the probabilistic weights of their database, making the diagnostic agreement continuously improve. Soon, symptom analysers will be able to provide useful information for the performance of clinical work (e.g., regarding sensitivity and specificity of symptoms for diseases, prevalence of diseases) closing the circle of collaboration between professionals-new technologies. Therefore, symptom analysers could be useful tools for medical personnel and other health professionals [20].

The variables that we use from the hospital admission prediction model have not undergone a multicentre validation process that includes all patients who come to the emergency room. On the other hand, in the original publication [12] it was not valued independently in the different levels of classification, so we did not have previous data of its possible applicability to the group of less complexity studied and, therefore, with lower forecast of need for hospital admission

In our project we used a nurse to feed the system with the patient's answers and answer their questions, without interfering with the symptoms that the patient wanted to expose. Herrick et al (26), in a study on the usability of a self-administered questionnaire for emergency diagnosis, found that $86 \%$ did not require assistance. Those who needed help were older $(54 \pm 19)$ years. In our sample, $30 \%$ are in the 50-69 age group. The errors in the participants of the study occurred during the interviews using a pencil instead of a touch screen. Despite this, in our project we opted for the help in the registration of the questionnaire.

In recent years, powerful initiatives have emerged to help physicians make decisions, in both diagnosis and therapeutics [35]. The results in this paper indicate that an improvement could be made in the Mediktor diagnostic agreement, as in similar devices, with the feedback of medical comments after its use, for its use as a diagnostic aid tool in the emergency department. With this improvement of easily expected agreement, the possibility of its use as a tool for the streamlining of the care process is opened. In a process with a high level of basic protocolization, such as emergency care, a rapid initial approach to probable syndromic diagnoses would allow the suggestion of basic protocolized complementary tests, especially interesting in a healthcare setting in which the presence of personnel in training is frequent. This could represent a contribution of a tool such as Mediktor as a complementary element to the triage, to improve the adequacy of complementary tests requested in the emergency, to improve the initial diagnostic orientation, to generate a time saving in the urgency process and, finally, to improve the safety in the assistance of the external hospital emergency.

\section{CONCLUSIONS}

The level of concordance of the first ten diagnoses suggested by Mediktor with respect to the final diagnosis of the patients was $76.5 \%$, higher than that published in similar programs. Its accuracy, like that of other comparable programs, is amenable to improvement with feedback from actual final diagnoses and medical comments.

The assignment of Mediktor levels, in this group of urgent patients of low complexity, does not coincide with that assigned by the Manchester system, which could indicate a different classification model. The classification of Mediktor in this segment of patients shows that a higher level of severity corresponds to a greater number of hospital admissions, hospital readmissions and revisits to emergencies at 30 days, although without statistical significance.

It is expected that the application has utility as a complement to the triage, to streamline the diagnostic approach, improve the adequacy of request for complementary tests and reduce waiting times in the emergency services in a protocolized action model.

\section{REFERENCES}

[1] Peiró S, Librero J, Ridao M, Bernal-Delgado E. Variabilidad en la utilización de los servicios de urgencias hospitalarios del Sistema Nacional de Salud. Gac Sanit. January 2010;24(1):6-12.

[2] Sarría Santamera A, Prado Galbarro J, Quintana Díaz M, Martínez Virto A. [Determinants of utilization of emergency departments in Spain]. Aten Primaria. July 2015;47(6):386-8.

[3] Informe Anual del Sistema Nacional de Salud 2016. https://www.msssi. gob.es/estadEstudios/estadisticas/sisInfSanSNS/tablasEstadisticas/ InfAnSNS.htm Access 25/03/2018.

[4] Jiménez JG. Clasificación de pacientes en los servicios de urgencias y emergencias: Hacia un modelo de triaje estructurado de urgencias y emergencias. Emergencias. 2003;15:165-74.

[5] Miró Ò, Salgado E, Bragulat E, Junyent M, Asenjo MA, Sánchez M. Estimación de la actividad en urgencias y su relación con la provisión de camas de hospitalización. Med Clínica. 2006;127(3):86-9.

[6] Martín-Sánchez FJ, González-Del Castillo J, Zamorano J, Candel FJ, González-Armengol JJ, Villarroel P, et al. El facultativo, un elemento necesario en el triaje de un Servicio de Urgencias en un hospital terciario. Emergencias. 2008;20:41-7.

[7] Dent AW, Weiland TJ, Vallender L, Oettel NE. Can medical admission and length of stay be accurately predicted by emergency staff, patients or relatives? Aust Health Rev. 2007;31(4):633-41.

[8] Clesham K, Mason S, Gray J, Walters S, Cooke V. Can emergency medical service staff predict the disposition of patients they are transporting? Emerg Med J EMJ. October 2008;25(10):691-4.

[9] Beardsell I, Robinson S. Can emergency department nurses performing triage predict the need for admission? Emerg Med J. 2010; emj-2010.

[10] Burch V, Tarr G, Morroni C. Modified early warning score predicts the need for hospital admission and inhospital mortality. Emerg Med J. 2008;25(10):674-8.

[11] Van der Wulp I, Schrijvers A, Van Stel H. Predicting admission and mortality with the Emergency Severity Index and the Manchester Triage System: a retrospective observational study. Emerg Med J. 2009;26(7):506-9.

[12] Elvira MC, Fernández C, González DCJ, González AJ, Villarroel P, Martín SF.Modelo predictor de ingreso hospitalario a la llegada al servicio de Urgencias [Prediction model for in-hospital admission in patients arriving in the Emergency Department]. An Sist Sanit Navar. 2012 MayAug;35(2):207-17.

[13] Alonso CF, Armengol JJG, Perdigones J, Ferrer MEF, del Castillo JG, Sánchez FJM. La utilidad de la escala Identification of Seniors at Risk 
(ISAR) para predecir los eventos adversos a corto plazo en los pacientes ancianos dados de alta desde una unidad de corta estancia. Emerg Rev Soc Esp Med Urgenc Emerg. 2015;27(3):181-4.

[14] Kovacs G, Croskerry P. Clinical decision making: an emergency medicine perspective. Acad Emerg Med. 1999;6(9):947-52.

[15] Schwartz LR, Overton DT. Emergency department complaints: a one-year analysis. Ann Emerg Med. 1987;16(8):857-61.

[16] Dunn JD. Malpractice in the emergency department. Ann Emerg Med. 1985;14(1):87-8

[17] Schiff GD, Hasan O, Kim S, Abrams R, Cosby K, Lambert BL, et al Diagnostic error in medicine: analysis of 583 physician-reported errors. Arch Intern Med. 2009;169(20):1881-7.

[18] Newman-Toker DE, Pronovost PJ. Diagnostic errors - the next frontier for patient safety. Jama. 2009;301(10):1060-2

[19] Farmer SEJ, Bernardotto M, Singh V. How good is Internet self-diagnosis of ENT symptoms using Boots WebMD symptom checker? Clin Otolaryngol. 2011;36(5):517-8.

[20] Semigran HL, Levine DM, Nundy S, Mehrotra A. Comparison of Physician and Computer Diagnostic Accuracy. JAMA Intern Med. 2016;176(12):1860.

[21] Morita T, Rahman A, Hasegawa T, Ozaki A, Tanimoto T. The Potential Possibility of Symptom Checker. Int J Health Policy Manag. 05 de 2017;6(10):615-6.

[22] Wyatt JC. Fifty million people use computerised self-triage. BMJ. 8 de julio de 2015;351:h3727.

[23] Miller RA. Medical diagnostic decision support systems — past, present, and future: a threaded bibliography and brief commentary. J Am Med Inform Assoc. 1994;1(1):8-27.

[24] Kawamoto K, Houlihan CA, Balas EA, Lobach DF. Improving clinical practice using clinical decision support systems: a systematic review of trials to identify features critical to success. Bmj. 2005;330(7494):765.

[25] Benaroia M, Elinson R, Zarnke K. Patient-directed intelligent and interactive computer medical history-gathering systems: a utility and feasibility study in the emergency department. Int J Med Inf. 2007;76(4):283-8.

[26] Herrick DB, Nakhasi A, Nelson B, Rice S, Abbott PA, Saber Tehrani AS, et al. Usability characteristics of self-administered computer-assisted interviewing in the emergency department: Factors affecting ease of use, efficiency, and entry error. Appl Clin Inform. 2013;4(2):276-92.

[27] Zachariasse JM, Seiger N, Rood PPM, Alves CF, Freitas P, Smit FJ, Roukema GR, and Moll HA. Validity of the Manchester Triage System in emergency care: A prospective observational study. PLoS One. 2017; 12(2): e0170811.Published online 2017 Feb 2. doi: 10.1371/journal. pone. 0170811

[28] Semigran HL, Linder JA, Gidengil C, Mehrotra A. Evaluation of symptom checkers for self diagnosis and triage: audit study. bmj. 2015;351:h3480.

[29] Barriga EM, Ferrer IP, Sánchez MS, Baranera MM, Utset JM. Experiencia de Mediktor ${ }^{\circledR}$ : un nuevo evaluador de síntomas basado en inteligencia artificial para pacientes atendidos en el servicio de urgencias. Emerg Rev Soc Esp Med Urgenc Emerg. 2017;29(6):391-6.

[30] Chiu HS, Chan KF, Chung CH, Ma K, Au KW. A comparison of emergency department admission diagnoses and discharge diagnoses: retrospective study.Hong Kong j.emerg.med. 2003;10:70-75

[31] Fordyce J, Blank FS, Pekow P, Smithline HA, Ritter G, Gehlbach S, Benjamin E, Henneman PLErrors in a busy emergency department.Ann Emerg Med. 2003 Sep;42(3):334-6.

[32] Ben-Assulia O, Sagib D,Leshnoc M, Ironib A, ZivImproving A. Diagnostic accuracy using EHR in emergency departments: A simulation-based study. Journal of Biomedical Informatics 55 (2015) 31-40.

[33] Rowe AK, de Savigny D, Lanata CF, Victora CG. How can we achieve and maintain high-quality performance of health workers in low-resource settings? Lancet Lond Engl. 2005;366(9490):1026-35.

[34] Medrano IH, Guijarro JT, Belda C, Ureña A, Salcedo I, Espinosa-Anke L, et al. Savana: Re-using Electronic Health Records with Artificial Intelligence. International Journal of Interactive Multimedia and Artificial Intelligence. 2018;4(Special Issue on Big Data and e-Health).

[35] González-Ferrer A, Seara G, Cháfer J, Mayol J. Generating Big Data Sets from Knowledge-based Decision Support Systems to Pursue Value-based Healthcare. International Journal of Interactive Multimedia and Artificial Intelligence. 2018;4(Special Issue on Big Data and e-Health).

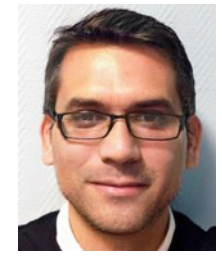

\section{Juan Carlos Nazario Arancibia}

Born in Trujillo (Perú) in February 1981. Graduated in Medicine from the Universidad Antenor Orrego Medical School. Specialization in Preventive Medicine and Public Health at Hospital Universitario Clínico San Carlos in Madrid. Master's Degree in Public Health by Escuela Nacional de Sanidad, Madrid. Master's Degree in HealthCare Administration by Universidad Pompeu Fabra Barcelona School of Management. He currently serves as member of Innovation Unit at Hospital Clínico San Carlos as Innovation Manager. Research interests: Innovation, Agile methodologies, Lean Healthcare, Big Data.

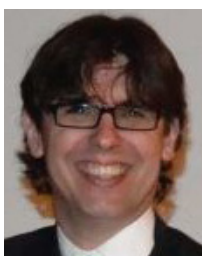

Francisco Javier Martín-Sánchez

Born in Madrid, Graduated in Medicine in 1999 from Universidad Autónoma de Madrid Medical School. Specialization in Geriatrics at Hospital Universitario Clínico San Carlos 2000-2004, PhD (Universidad Complutense, Madrid). $\mathrm{He}$ is the member of the ICASEMES and GREAT group. His field of research has focused on the field of geriatric cardiology and the author of several publications in the area of acute heart failure in the elderly.

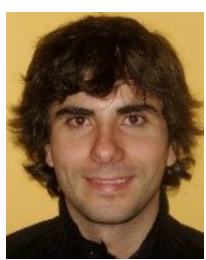

\section{Angel Luis Del Rey-Mejías}

Born in Madrid, February 1982. Superior Technician in Administration of computer systems in Arboleda (2004). Graduated in Psychology in 2010 from Universidad Complutense de Madrid (UCM) Psychology School. Master Degree in Methodology of behavior and health sciences in Universidad Autónoma de Madrid (2012) and Master Degree in Mental health research at CIBERSAM (2014). He currently serves as member of Innovation Unit at Hospital Clínico San Carlos as Innovation Manager. Publications (2017): Parellada, M., PinaCamacho, L., Moreno, C., Aleman, Y., Krebs, M.O., Desco, M., MerchánNaranjo, J., Del Rey-Mejías, A., Boada, L., Llorente, C. and Moreno, D., 2017. Insular pathology in young people with high-functioning autism and firstepisode psychosis. Psychological medicine, 47(14), pp.2472-2482. Esguevillas, Á., Díaz-Caneja, C.M., Arango, C., Del Rey-Mejías, Á.L., Bernardo, E.G., Delgado, C., Clarkin, J.F. and Carrasco, J.L., 2017. Personality organization and its association with clinical and functional features in borderline personality disorder. Psychiatry research. Research interests: Research, Innovation, Psychiatry, Machine Learning, Big Data, Business Intelligence.

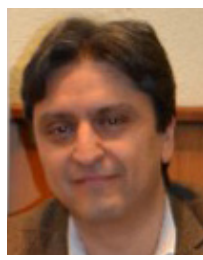

\section{Juan González del Castillo}

Born in Madrid, July 1973, Graduated in Medicine in 1997 from Universidad de Extremadura Medical School. Specialization in Internal Medicine at Hospital Universitario Clinico San Carlos (HUCSC) 1999-2004, $\mathrm{PhD}$ (Universidad Complutense, Madrid) in 2006. Coordinator of the Infectious Disease Group of the Spanish Emergency Medicine Society. Member of the "Revista Española de Quimioterapia" journal editorial board. Section Editor of Emergencias Journal. Board member of the Spanish Quimiotherapy Society. Senior doctor in the Emergency Department, Hospital Clinico San Carlos. One hundred and twenty-six articles published in indexed journals.

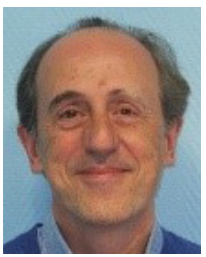

\section{Joan Chafer Vilaplana}

Born in Barcelona in 1958. Graduated in Medicine in 1958. Specialist in Internal Medicine since 1981 after an MIR program at the Hospital Clinico San Carlos. Worked in Clinical medicine and research at King's College Hospital in London, The Royal London Hospital and back in Madrid at the liver unit of the Fundación Jiménez Díaz. Since 1999 works in research management and innovation, initially at Hospital Universitario La Paz and currently at the Innovation Unit of the Hospital Clinico San Carlos. Between 2008 an 2012 was also responsible for IT and Information Systems at the latter hospital. 


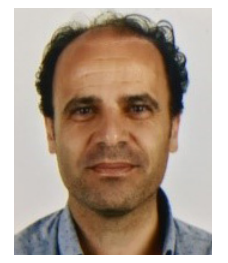

Miguel Angel García Briñón

Born in Salamanca, March 1970, nursing in 1994 from the Universidad de Salamanca, nursing degree from Universidad Complutense de Madrid in 2011, master's in management of health services and health companies from Universidad Complutense de Madrid in 2012.I worked as a nurse from 1996 to 2000 in different intensive care units and until 2010 in critical care of the San Carlos Hospital in Madrid. Nurse Emergency Supervisor Department of San Carlos Hospital from 2010. Member of the research group "OGS 25 pathology of urgencies and emergencies" from 2011.

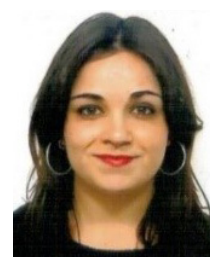

María del Mar Suárez-Cadenas

Born in Almería in 1993. Graduated in 2015 by the University of Almería with a degree in Nursing. Official Master in Sexology, sexual education and sexological advice by the University Camilo José Cela in 2017. Has worked as a nurse in different emergency department since 2015 until now. Currently part of a researching group "OGS 25 pathology of urgencies and emergencies".

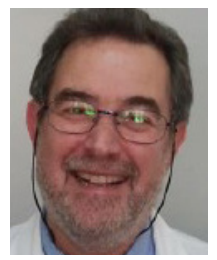

Germán Seara

Born in Madrid, March 1951, Graduated in Medicine in 1975 from Universidad Complutense de Madrid Medical School. Specialization in Pediatrics at Hospital Universitario Clínico San Carlos (HUCSC) 197680, Madrid. FIS Scholarship for Extension Studies at Northwick Park Hospital \& Clinical Research Center, Harrow, UK, Top Managerial Programme in King's Fund, London/UK and ENS, Madrid, Spain. He was former Chief Medical Officer at Hospital Clinico San Carlos and in other hospitals and he is currently appointed to the Innovation Unit of HUCSC. Recent Publications: Integración clínica en el paciente crónico, Carretero L, Comes N, Borrás A, Rodríguez Balo A y Seara G. Enferm Clin. 2014;24(1):35-43. G. Seara, A. Payá, J. Mayol, ValueBased Healthcare Delivery in the Digital Era. European Psychiatry March 2016, Vol 33S pp S46. Generating Big Data Sets from Knowledge-based Decision Support Systems to Pursue Value-based Healthcare A González-Ferrer1, G Seara, J Cháfer, J Mayol. IJIMAI 2018;IV(7):42-6. Research interests: health care, innovation. Dr. Seara memberships: Asociación Española de Pediatría.

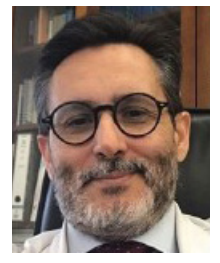

Julio Mayol

Born in Madrid, July 22nd, 1963, Graduated with honors in Medicine in 1988 and $\mathrm{PhD}$ summa cum laude in Medicine in Medicine in 1992, both from Universidad Complutense de Madrid Medical School. Specialization in general surgery at Hospital Clínico San Carlos 1991- 1995. Fellow in Surgery at Beth Israel Deaconess Medical Center Harvard Medical School. Attending surgeon. Associate Professor of Surgery. Chief of the Division of Colorectal Surgery. Full Professor of Surgery at Universidad Complutense de Madrid Medical School. Visiting Professor at Wayne State University. Chief Medical Officer at Hospital Clinico San Carlos. Publications: 1. Chapman SJ, Mayol J, Brady RR. Twitter can enhance the medical conference experience. BMJ. 2016 jul 19;354: i3973. - Mayol Martinez J. Innovation in Surgery. Cir Esp. 2016 Apr;94(4):207-9. Maeso S, Reza M, Mayol JA, Blasco JA, Guerra M, Andradas E, Plana MN. Efficacy of the Da Vinci Surgical System in Abdominal Surgery Compared with That of Laparoscopy: A Systematic Review and Meta- Analysis. Ann Surg. 2010 Aug;252(2):254-62. PMID: 20622659. Research interests: colorectal surgery, biomedical technology, innovation, Prof. Julio Mayol memberships: American Gastroenterological Association, Society for Surgery of the Alimentary Tract, Asociación Española de Cirujanos, Sociedad Española de Investigaciones Quirúrgicas. 